\title{
INITIAL EXCITATION ISSUES OF SYNCHRONOUS sciendo GENERATOR WITH VSI INVERTER IN VARYING ROTATIONAL SPEED OPERATION
}

doi:10.2478/mape-2018-0048

Date of submission of the article to the Editor: 04/2018

Date of acceptance of the article by the Editor: $07 / 2018$

MAPE 2018, volume 1, issue 1, pp. 377-383

\section{Dr Eng. Maciej Kozak}

Maritime University of Szczecin, Poland

\begin{abstract}
Synchronous self-excited generators still are and probably will be the most popular 3-phase alternators installed in inland power stations so onboard of seagoing ships. Because of fuel savings and environmental restrictions Diesel, dual-fuel and gas propulsion engines for alternators of wide-range varying revolutions drives are increasingly used. There must be efficient way of creating 3-phase voltages of desired constant parameters ensured when generator produces variable amplitudes and frequencies of voltages because of changing rotational speed. As the control method modified field oriented control widely used with squirrel cage induction machines was chosen. This control method involves decoupling of currents and control voltages to flux and torque components and keeping them in optimal (orthogonal) condition. In order to obtain proper excitation and operation of such generator several factors have to be taken into account. Nonlinear dependence of voltage generated from rotational speed of self-excited synchronous generator is one of the factors that affects initial excitation process thus specific control method while generator startup. Theoretical background of synchronous generator excitation and voltage source inverter adopted FOC control method along with experimental results obtained in laboratory test bench of $5,5 \mathrm{~kW}$ generator and conclusions were presented.
\end{abstract}

Keywords: Synchronous generator, initial excitation, FOC control, voltage source inverter, synchronization.

\section{INTRODUCTION}

Field oriented control (Rupprecht et al., 1980) is widely used in many variants as a robust control method for permanent magnet electrical motors (Merzoug, and Naceri, 2008) and generators of the same type (Abdelrahem et al., 2017). In the most cases of generating mode constant or slightly changing rotational speed of synchronous generator is assumed, while new types of power plants has emerged (Kambrath et al., 2018) which allow variable speed operation just to obtain fuel consumption decrease. These power plants are operating mainly with use of synchronous self-excited machines connected to controlled rectifiers which maintain proper level of DC voltage (ABB onboard DC grid). Control of voltage level allows easy control of power balance and power shedding between voltage sources connected in parallel. Use of controlled rectifiers is not very convenient way of optimal and precise control of voltages with field oriented control method. To get all benefits from using self-excited synchronous generator with FOC controlled inverter other control scheme should be utilized. To obtain full field oriented programmable control voltage source inverter (VSI) was used for simulation and on experimental test bench.

One of the problems that can be found in practical applications is a need of different parameters set use for startup procedures than steady state operation. It is clear that transient processes in varying speed generators are more demanding and set of initial parameters must be different and cover wide range (900 to 1500 rpm's) of rotational speeds of generator. Each rotational speed of alternator creates different value of back emf on the terminals of generator. 
This property entails a necessity of finding a way to proper and safe for machine side inverter circuitry excitation.

\section{PRINCIPLE OF SYNCHRONOUS MACHINE OPERATION AND CONTROL}

The control principle of the synchronous generators with electrical excited winding is well known, considering the frequency and voltage control by means of the active and reactive power adjustment. The active power is coming from the mechanical prime mover while the reactive power is commanded and controlled with the DC current excitation winding and voltage regulator. In most case the two control loops are operating separately each to others with use of RPM's governor and voltage regulator. This kind of operation may be considered as a scalar control procedure, which disregards some phenomena, i.e. the coupling effect between electrical axis the synchronous generator (Imecs et al., 2008). The vector control is based on the field-orientation principle. It can be used as an AC induction motor drives control, but also for squirrel cage generator running. Because of its performance during transient operation modes, it comes quite close to direct current machines. The mathematical background of the dynamic model and vector control of AC machine is given by the spacephasor theory (Kozak et al., 2016). Thanks to field oriented control simplicity of DC machines control got into the AC motors and generators methods. The rotor flux oriented synchronous machine model is similar to a shunt excited direct current machine. It is suitable for the simulation of the synchronous generator operation, but the control will be realized with the field oriented model considering the resultant stator flux. This model leads to the analogy with the compensated DC machine, which allows the independent control of the two variables that produce the machine torque (Imecs et al., 2008), (Balog et al., 2011). In Figure 1 there are shown the stator field oriented components of the stator current:

$$
i_{s}=i_{s d \lambda}+\mathrm{j} i_{s q \lambda}
$$

while the armature coil flux equals to:

$$
\Psi_{s s}=\Psi_{s s d \lambda s}+\mathrm{j} \Psi_{s s q \lambda s}=L_{m d} i_{s d \lambda}+\mathrm{j} L_{m q} i_{s q \lambda}
$$

where:

$\lambda_{s}$ is the angular position of the resultant stator flux $\psi_{s}$.

In generating mode, the quadrature component of the armature flux $\Psi_{\text {ssd }}$, which determines the active power and dc intermediate circuit voltage will be negative due to the reversed active energy flow. Flux denoted as $\psi_{\text {ssad }}$ is also negative, due to its demagnetizing character. This flux corresponds to the reactive power. The exciting current has influence on an active component, which produces the torque in the air-gap. Because of decoupled control the longitudinal component of the field oriented exciting current contributes to the magnetizing phenomena in the synchronous machine. Neglecting the stator resistance, the triangle of the machine powers become also similar to that of the stator currents (Imecs et al., 2008). In such a case, active and reactive power can be controlled independently by means active and reactive stator current components.

To control the power flow, the stator current has to be oriented according to the magnetizing direction of the resultant stator flux $\psi_{s s q \lambda}$, realized by a Clarke and Park ( $\alpha-\beta$ and $\left.d-q\right)$ transformations (see Fig. 2). In order to have a simpler control for alternator some simplification have to be taken into consideration regarding the produced torque. The load torque can be controlled by controlling the torque angle. In the constant torque angle control strategy, the $d$ axis current is kept zero for all of the operation time, while the vector current is aligned with the q axis in order to maintain the torque angle equal to $90^{\circ}$. This is one of the most used control strategy because of its simplicity. 


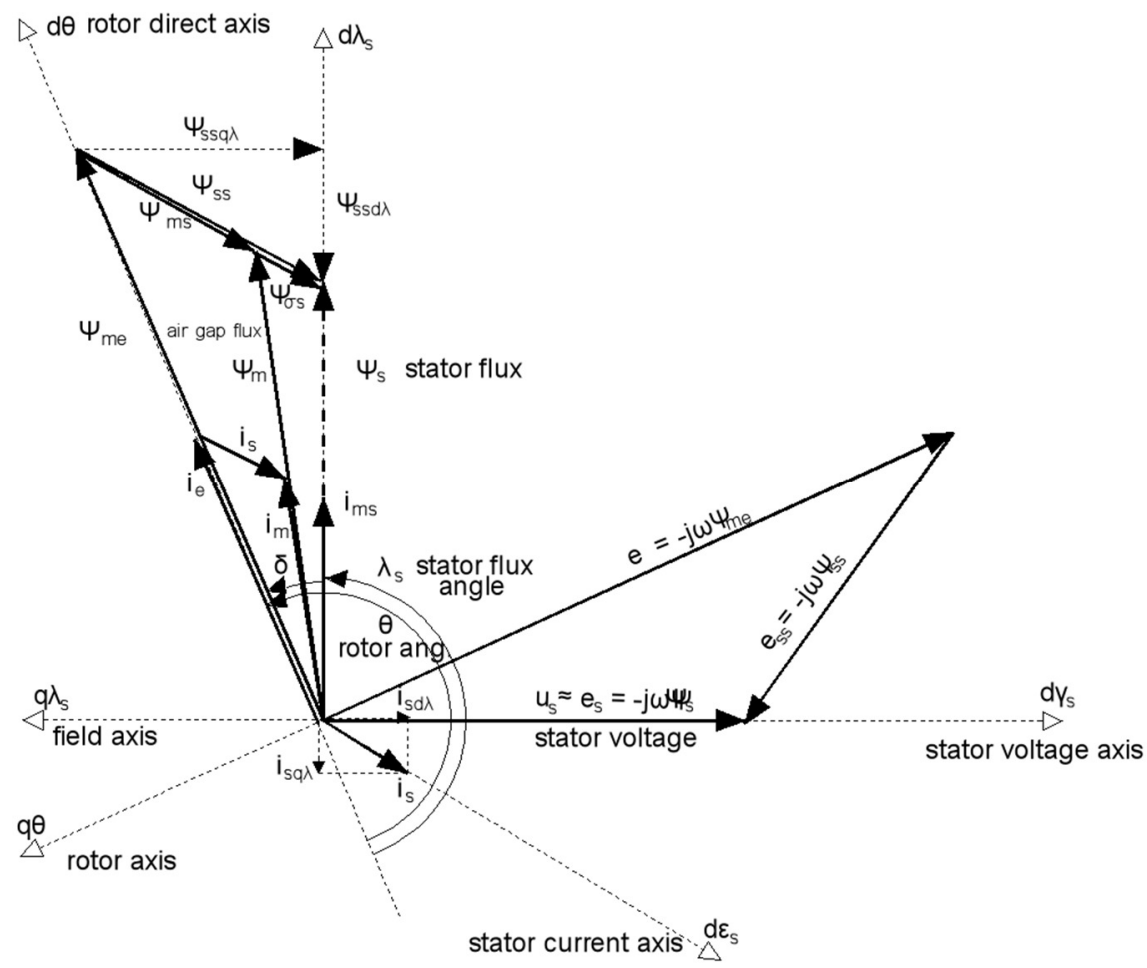

Fig. 1. Diagram of the synchronous generator with leading stator current, and the stator-field oriented space phasors of the stator current

The torque equation for a synchronous generator, taking into account both isd and isq currents is the one derived in:

$$
T_{e}=\frac{3}{2} \mathrm{p}\left[\Psi_{m} i_{s q}+\left(L_{d}-L_{q}\right) i_{s q} i_{s d}\right]
$$

where: $p$ is a number of pole pairs and $\psi_{m}$ is field winding flux.

After substituting the $d-q$ currents in equation (3) and after a few simplifications the torque value is the one presented in equation (4).

$$
T_{e}=\frac{3}{2} \mathrm{p} \Psi_{m} i_{s q}
$$

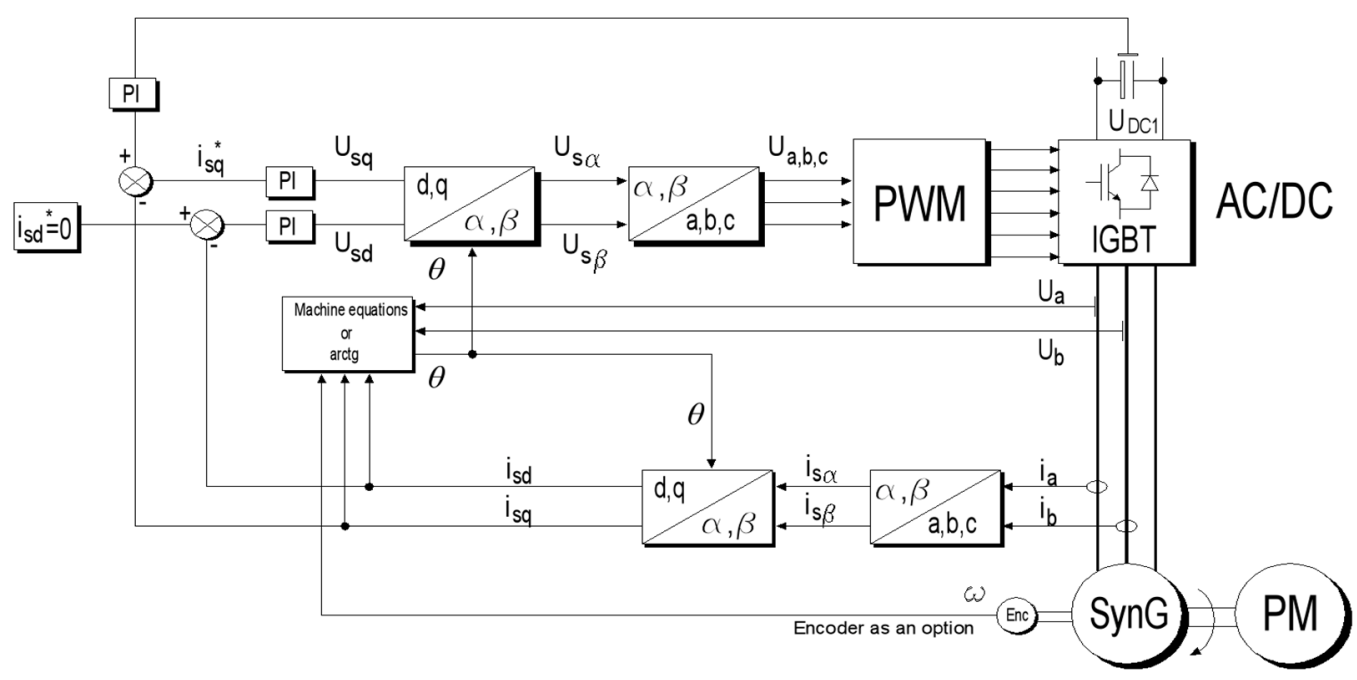

Fig. 2. Vector control structure of the self-excited synchronous generator with stator-field orientation 
From above equation it can be easily observed that the control property is very simple to implement, just by representing the linearization between the torque and machine current. All control of synchronous generator in presented method lies in commanding proper value of active current isq. The control of active current in the startup time incorporates limits that should be not exceeded in the range of all investigated rotational speeds. After excitation time the limits and restrictions are eliminated and system works purely in power generating mode.

\section{SIMULATION AND EXPERIMENTAL RESULTS OF THE PRESENTED SYSTEM}

Along with VSI consisting of IGBT's bridge, the self-excited synchronous generator of $5,5 \mathrm{~kW}$ driven by squirrel cage motor was used for purpose of experimental investigation. To obtain proper intermediate direct current voltage level on terminals of electric generator has to be controlled in unique way. This feature is crucial for operation of the whole designed system. Because of self-excitation and use of the compound transformer feeding voltage regulator in synchronous generator there is no need to independent control of reactive current control. The parameters controlled by machine side inverter are so called active current isq. and magnetizing current isd.

The active current controlled by PI controller holds DC voltage value on intermediate circuit while magnetizing current equals to zero even at transient processes. In the steady state the values of active and reactive currents are constant thus easy to control with PI regulators. Such control type is well-known in drive applications but still has a little use in generator applications. The advantage of used method is easy control of DC voltage thus power distribution with limiting only active current $i_{\text {sq. }}$. This property was utilized while startup process and relies on smooth increase of current limit with decreased voltage of intermediate circuit. As the experiments showed only aforementioned combination of controller's parameters provided good results in excitation of alternator rotating within assumed speed limits.

As it can be seen on the Figure 2 reactive current $i_{s d}$ is set to zero because proper excitation current composed of vector sum of resulting phase voltages and phase currents is provided by compound transformer, capacitors and brushes with slip rings.

The excitation winding of the synchronous generator receives power from the rotating rectifier, which is powered by a secondary coil of the compound current transformer. The compound transformer contains current coil and a voltage coil. All excitation direct current flows through two slip rings and brushes from voltage regulator into excitation windings. Still it is compound exciter which utilizes information of currents, voltages and phase shift to create proper, depending on load power factor rotor current. Most of synchronous generators with regulators are designed for continuous work with almost constant rotational speed, thus the speed change results in voltage changes. As it can be seen in the Figure 3 while no-load startup process synchronous eclectically excited generator's voltage changes in nonlinear way.

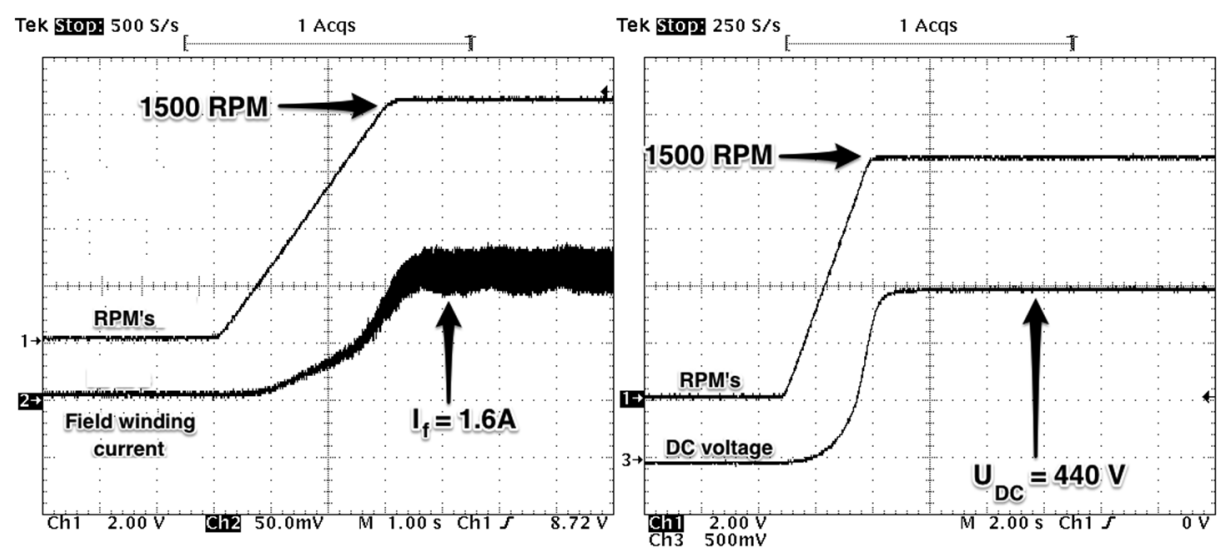

Fig. 3. Influence of rotational speed on field current and waveforms close-up of rectified field winding current 
This property of synchronous generator causes the control of initial process of excitation needs a special procedure that includes altered regulators coefficients and lowered set point of intermediate circuit DC voltage.

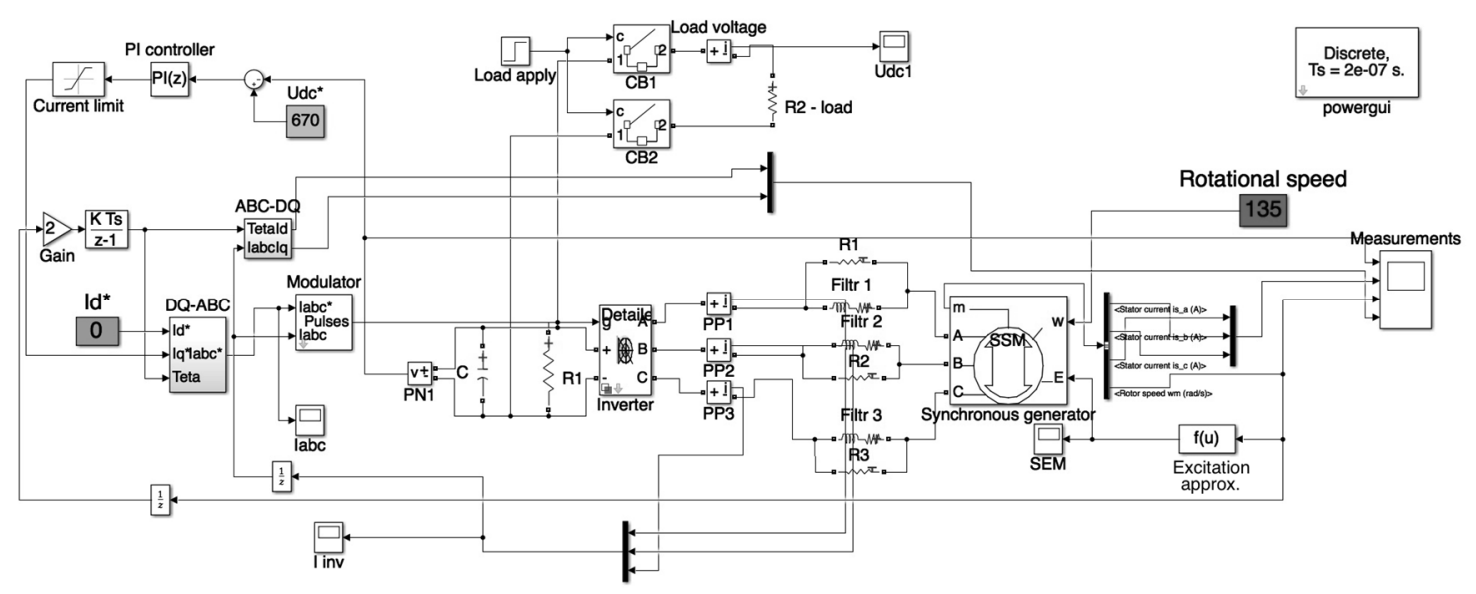

Fig. 4. Scheme of investigated system prepared in Matlab/Simulink.

To create real time working application on laboratory test bench at first the simulation model was prepared. In order to obtain simple structure of investigated system model there were some simplifications have been made. First of all, the modulator is a hysteresis current type instead of space vector modulation usually found in real time application. As the model of synchronous machine the SI units simplified machine model was chosen with parameters changed to actual values of real machine.

In such model the excitation voltage depends on generators rotational speed. After testing the target synchronous machine, a set of measured voltages were fitted into the function describing the dependence of voltage on RPM's. This approximation function was implemented into a model to obtain responses similar to experimental results. As it turned out in simulations results, system needs different set of parameters for startup and excitation. Because of overvoltage protection of circuitry DC voltage shouldn't exceed 800 volts at any time, so regulators must have different set of data for gain and integration coefficients.
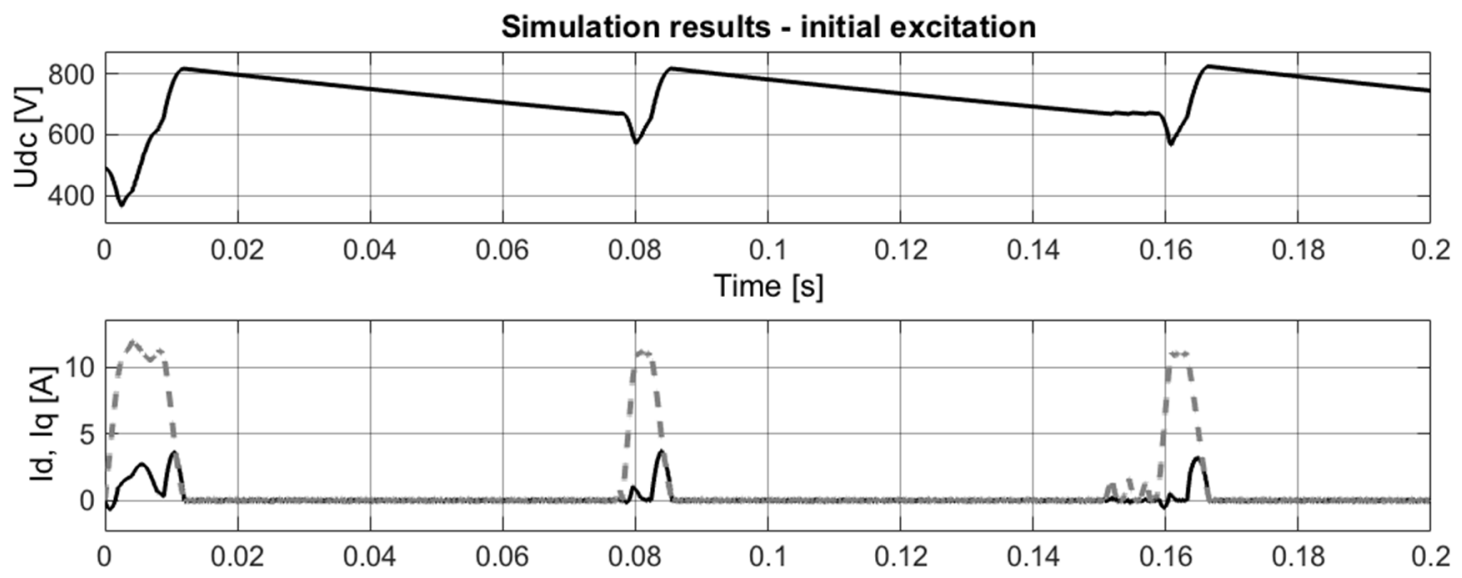

Fig. 5. Waveforms obtained in simulation researches. Visible occurrence of voltage excess over 800 volts.

The overcurrent protection action led to some current controllers' modifications. On the basis of simulation results real time system using DSP-FPGA controls was prepared. The 
preparation of the experimental desk bench means mainly programming DSP signal processor with VisualDSP++ language, compiling program and transferring it to processor. The DSP program calls in interruptions FPGA and transfers data in and out to logic array. The FPGA board has implemented analog to digital converters that are connected to current and voltage transducers. The Park and Clarke transforms and actual rotor angle are calculated in real-time operation of proposed system. Proposed system operates in so called sensorless mode what means lack of encoder use. in practical solutions, an encoder is required for increased reliability but for the most of the time operations are purely mathematical with use of machine state simulators or observers. In the presented case rotor angle was calculated with use of trigonometric function and projections of currents in $\alpha-\beta$ plane. Tests carried out in the experimental test-bench were conducted in order to find optimal settings of regulators allowing safe and reliable start-up of the synchronous generator. The first tests included excitation at various rotational speeds of the generator. The results were similar to obtained in simulations - excitation with plain regulators settings was not successful especially for lower values of rotation. It can be explained for integral part of $\mathrm{PI}$ controller. When rotational speed is low, resulting DC voltage has a low value so the difference between commanded and actual value is significant, so the action of the regulator integral part is quite abrupt. This leads to oscillations and DC voltage excess out of safe limit so the currents what at the end triggers safety features and system shutdown. Some of experimental results depicting above issues are shown in following Figures.

The first two oscillographs in Figure 6 are presenting failed initial excitation attempts obtained for different rotational speeds. Because of excitation process rapid nature shutdown of system was caused by quick increasing current value rather than high voltage on DC side of inverter. After altering coefficients and setting some ramps and limits on voltage and active currents the process of initial excitation was successful for assumed speed range. Startup operation while changing speed became possible what can be observed on both, lower waveforms in Figure 6 .
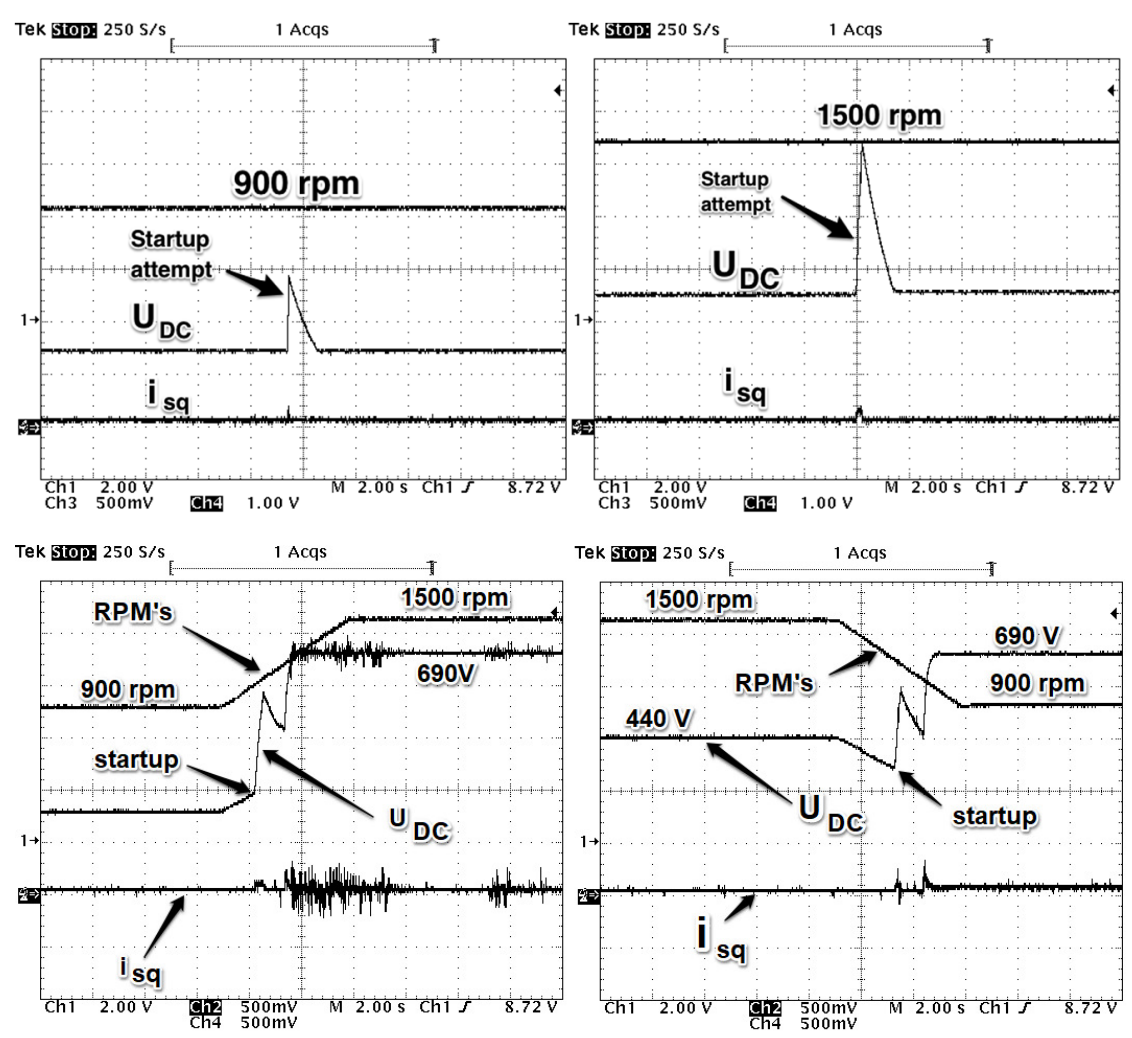

Fig. 7. Experimental results of initial excitation process and $U_{D C}$ voltage build-up while increasing and decreasing generator rotational speed. 


\section{CONCLUSION}

On the basis of researches conducted on the laboratory test bench the most important conclusions can be summarized as follows:

- It is possible to obtain proper excitation and startup process of inverter powered self-excited synchronous generator without making and modifications to embedded voltage regulator in the case of rotational speed in nominal range;

- The excitation process draws significant amount of energy what can cause oscillations in circuits operating with regulators coefficients fixed for certain values;

- Combination of commanded decreased DC voltage along with limited active current and it's increase ratio gives the satisfying results in proper startup and excitation process;

- Presented method was successfully implemented also to permanent magnet synchronous generator which presents almost linear dependency generated terminal voltage on rotational speed;

- In the experiments conducted on presented system stable work was achieved in whole assumed operational range.

The researches, laboratory equipment and software used in experiments was funded by program 1/S/1/IEiAO/2016.

\section{REFERENCES}

Abdelrahem, M., Hackl, C. M. and Kennel, R. (2017). Implementation and experimental investigation of a sensorless field-oriented control scheme for permanent-magnet synchronous generators. Berlin Heidelberg: Springer.

Balog, R. and Krein, P.T. (2011). Bus Selection in Multibus DC Microgrids. IEEE Transactions on Power Electronics, Volume 26 (3), pp. 860-867.

Imecs, M., Incze, I. and Szabo, C. (2008). Stator-Field Oriented Control of the Synchronous Generator: Numerical Simulation. In: 2008 International Conference on Intelligent Engineering Systems, ISSN 1543-9259.

Kambrath, J.K., Wang, Y., Yong-Jin, Y., Alexander, A.A., Liu, X. and Wilson, G. (2018) Modeling and control of marine diesel generator system with active protection. IEEE Transactions on transportation electrification, volume 4(1).

Kozak M., Bejger A. and Gordon R.(2016), Control of squirrel-cage electric generators in parallel intermediate dc circuit connection. Zeszyty Naukowe Akademii Morskiej w Szczecinie, Volume 45 (117), pp. 17-22.

Merzoug M.S., and Naceri F. (2008), Comparison of Field-Oriented Control and Direct Torque Control for Permanent Magnet Synchronous Motor (PMSM). World Academy of Science, Engineering and Technology International Journal of Electrical and Computer Engineering Volume 2(9).

Rupprecht, G., Werner L. and Nordby C.J. (1980), Field-Oriented Control of a Standard AC Motor Using Microprocessors, IEEE Transactions on Industry Applications Volume IA-16 (2).

Wenjie, C., Ådnanses, A.K., Hansen, J.F, Lindtjørn, J.O. and Tianhao, T (2010). Super-capacitors based hybrid converter in marine electric propulsion system. In: Proc. 19th Int. Conf. Elect. Mach. (ICEM), pp. 1-6. 